\title{
Modeling of uplift resistance of buried pipeline by geogrid and grid-anchor system
}

\author{
S. Reza Maljaei , Majid Mahdi , Hooshang Katebi ${ }^{2}$, A. Akbar Javadi ${ }^{4}$
}

\begin{abstract}
This paper presents an experimental and numerical analysis of the uplift resistance of pipelines buried in reinforced soil. The behavior of the system is studied using a set of laboratory experiments. The pull-out forces of some reinforcing pipelines are the most important factors affecting the uplift resistance. Buried elements like pipelines that have high pressure fluids or are under the high temperature, need to be reinforced in order to increase their pull-out resistance. One of the efficient methods to reinforcement, is increasing the involvement between pipe and soil, by using of geogrids and anchors. Grid-anchor is a recent method for increasing the pull-out resistance of soil, and is the method used in this study. The Digital Image Correlation or Particle Image Velocimetry (DIC/PIV) method is used for measuring the displacement in the field of experimental mechanism. We also examined the influence of parameters affecting on the soil. An experimental study was performed to investigate the uplift resistance of the pipelines buried in sand reinforced with this system. The experimental results demonstrate that, for the pipes with a diameter of $50 \mathrm{~mm}$, the grid-anchor system of reinforcement can increase the uplift capacity 2.4 times compared with the conventional geogrid and 4 times compared with non-reinforced sand. In the numerical modeling likewise, 23 experiments were back analyzed using the software FLAC3D. It became known that experimental tests stand good comparison with the numerical results.
\end{abstract}

Author Keywords: Digital Image Correlation; Particle Image Velocimetry; Buried pipelines; Geogrid; Grid-anchor; Physical modeling; deformations

\section{Introduction}

The interaction between the pipe, backfill material and the surrounding ground affects the behavior of buried pipelines. In design of pipelines, increasing the depth of the vertical cover is imperative to reduce the concentrated traffic loads imposed

\footnotetext{
${ }^{1}$ Research Assistant, Dept. of Geotechnical Engineering, Faculty of Civil Engineering, Univ. of Tabriz, 29 Bahman Blvd., Tabriz, Iran. Email: sr.maljaei93@ms.tabrizu.ac.ir

${ }^{2}$ Research Assistant, Dept. of Geotechnical Engineering, Faculty of Civil Engineering, Univ. of Tabriz, 29 Bahman Blvd., Tabriz, Iran. Email: m.mahdi@tabrizu.ac.ir

${ }^{3}$ Professor, Dept. of Geotechnical Engineering, Faculty of Civil Engineering, Univ. of Tabriz, 29 Bahman Blvd., Tabriz, Iran. Email: katebi@tabrizu.ac.ir

${ }^{4 *}$ Professor, Computational Geomechanics Group, Dept. of Engineering, Univ. of Exeter, Harrison Building, North Park Road Exeter, Devon EX4 4QF, UK. (corresponding author) Email: a.a.javadi@exeter.ac.uk Tel: +44 1392723640
} 
on a pipeline. The efforts to increase the depth of cover to mitigate the traffic loading is countered by the increase in the vertical and lateral earth pressures as well as the buoyancy forces (Mohri et al., 2001).

In this regard, greater resistance can be achieved by increasing the depth of pipe coverage. However, increasing the depth also increases the cost of the project. On the other hand, more time would be needed for excavation of deeper trenches and this is a very important factor for projects that involve long pipelines. Therefore, an efficient design should attempt to reduce the depth and enhance the uplift resistance of the buried pipes.

In this research, Digital Image Correlation with Particle Image Velocimetry (DIC/PIV) is used as an effective method to measure the displacements of soil particles around a buried pipe. In this method, photos were taken from the displacements of the soil particles around the buried pipeline. 300 photos were taken for each test and were analyzed in MATLAB.

\section{Review of Previous Works}

Research into the uplift resistance of buried pipelines and anchor plates has been extensively reported (Rowe and Davis, 1982; Trautmann et al., 1985; Dikin, 1994; Finch, 1999; White et al., 2001; Bransby et al., 2002; Cheuk et al., 2005; White, Cheuk et al., 2008; Choobbasti et al., 2009; Lee, 2010; Huang et al., 2014). Trautmann et al. (1985) developed a small-scale physical model for measuring the maximum uplift force of buried pipelines in dry sand as a function of the density of soil and depth of pipe. The results showed that, in loose sand the uplift resistance could be considerably lower in comparison with dense sand.

Studies based on finite element analysis have shown that grid-anchors are effective in improving the uplift characteristics of pipelines by about 4.5-6.5\% (Newson and Deljoui, 2006).

Thusyanthan et al. (2008) conducted a set of centrifuge model tests to study the uplift resistance of buried pipelines in cohesive soil, measuring the vertical displacement of pipe, excess pore pressure and soil cover strength. The main influencing parameters such as pipe exit rate, depth of soil and interval between burial and exploitation were studied. Selvadurai (1989) performed experiments on a pipe with diameter of $150 \mathrm{~mm}$ and suggested a method to enhance uplift resistance by placing geogrid on top of the pipe.

Faizi et al. (2015) studied the effect of increasing the geogrid compound on the uplift resistance of buried pipelines in loose sand. A pilot program consisting of 11 small-scale uplift experiments was carried out along with numerical modeling using PLAXIS 3D TUNNEL. Their findings indicated the importance of applying geogrid to enhance the uplift resistance.

One of the applications of geosynthetic-reinforced soils is to increase the bearing capacity of shallow spread footings. Recently, a new reinforced soil wall was introduced to improve the bearing capacity of the soil (Jacobs et al., 2016).

There have been several studies in this field with the main objective of assessing the system (Mosallanezhad et al., 2008; Alamshahi and Hataf, 2009; Mosallanezhad, Sadat Taghavi et al., 2016). The main idea behind this new system was to add grid-anchors to the regular geogrids. The anchors were made of $10 \times 10 \times 10 \mathrm{~mm}$ cubic plastics. The results showed that the grid-anchor system could increase bearing capacity 2.74 times from conventional geogrid and 4.43 times from nonreinforced sand (Kwang and Tang, 2019).

In principle, the purpose of physical modeling of a geotechnical phenomenon is to simulate soil behavior in natural loading conditions or to validate theoretical or numerical models. The very small size of the pre-failure deformations from one hand and the small scale of the geotechnical models on the other hand, make it difficult to measure displacement in comparison to the actual dimensions (Take, 2015).

The limits of strains in geotechnical processes indicate that the range of $0.01-1 \%$ strain is related to the servicability and pre-failure conditions. To assess the reliability of soil behavior in physical models in the context of the existing strains, these models must be equipped with a deformation measurement system that can identify the strains of $0.01 \%$ (corresponding to approximately $5 \mu \mathrm{m}$ displacement). Although modern techniques have increased the precision of strain measurement in physical testing (less than $0.001 \%$ ), these tools are very expensive and are subject to practical constraints. Mechanical measurement devices are usually located on the boundaries of the physical model, and because of the practical constraints and the small number of measurement points, they cannot fully represent the behavior of the pattern changes in the soil. Therefore, to find the deformation failure wedge in the models, the idea of using a transparent observation window to study the soil deformations and PIV analysis has been presented (Soga et al., 2019).

PIV analysis is usually done on a subset (or patch) of particles that are defined as portions of the moving masses whose deformation is analyzed (Kanitza et al., 2019; Nuria et al., 2017). On the other hand, Digital Image Correlation with Particle Image Velocimetry (DIC/PIV) has been widely used in the last two decades for various applications. This is a relatively simple, cost-effective and accurate method for measuring particle movement (White et al., 2003).

In this study, the application of grid-anchors and geogrids for improving the uplift resistance of buried pipelines in loose sand is examined. A program of experiments including 23 tests was carried out in parallel with numerical analysis using FLAC-3D. To increase the uplift resistance of buried pipelines, the anchors must be installed below the geogrid. Fig. 1 exhibits a schematic arrangement of the system. In this system, the anchors are made from cylindrical plastic elements, 3 $\mathrm{cm}$ in diameter and $1 \mathrm{~cm}$ in height attached to a geogrid net with elastic strips of $8 \mathrm{~cm}$ length. Each cable has its own local coordinate system. Fig. 2 shows the grid-anchor system used in this study. The properties of the materials used in the experimental work and numerical analysis are shown in Table 1. 


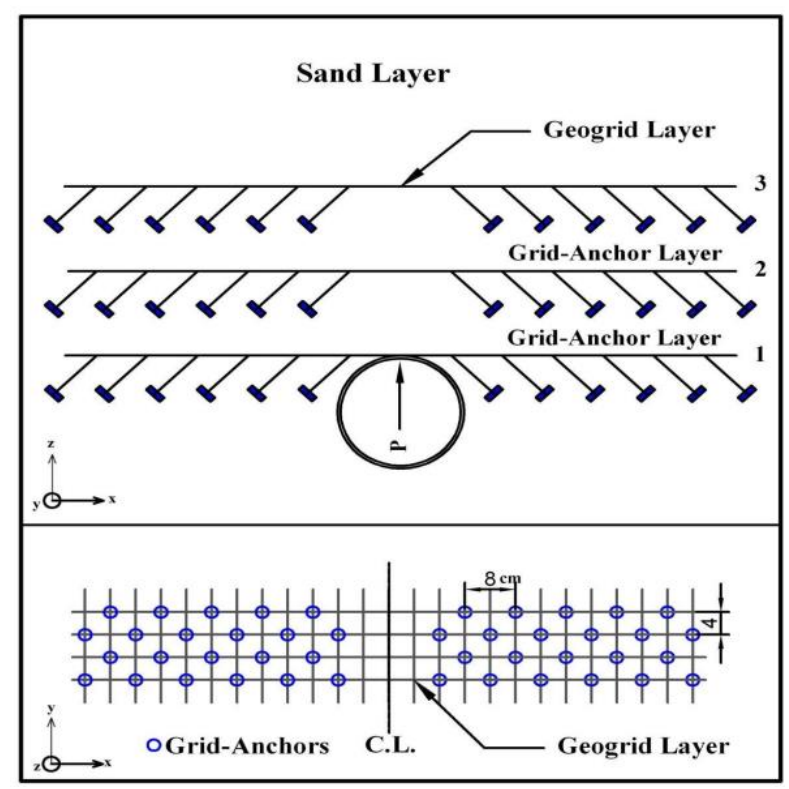

Fig. 1. Schematic model of the pipeline buried in grid-anchor reinforced soil

Fig. 2. Grid-anchor system used in this study

Table 1: Material properties of the reinforcement and sand used in the experiments and numerical modeling

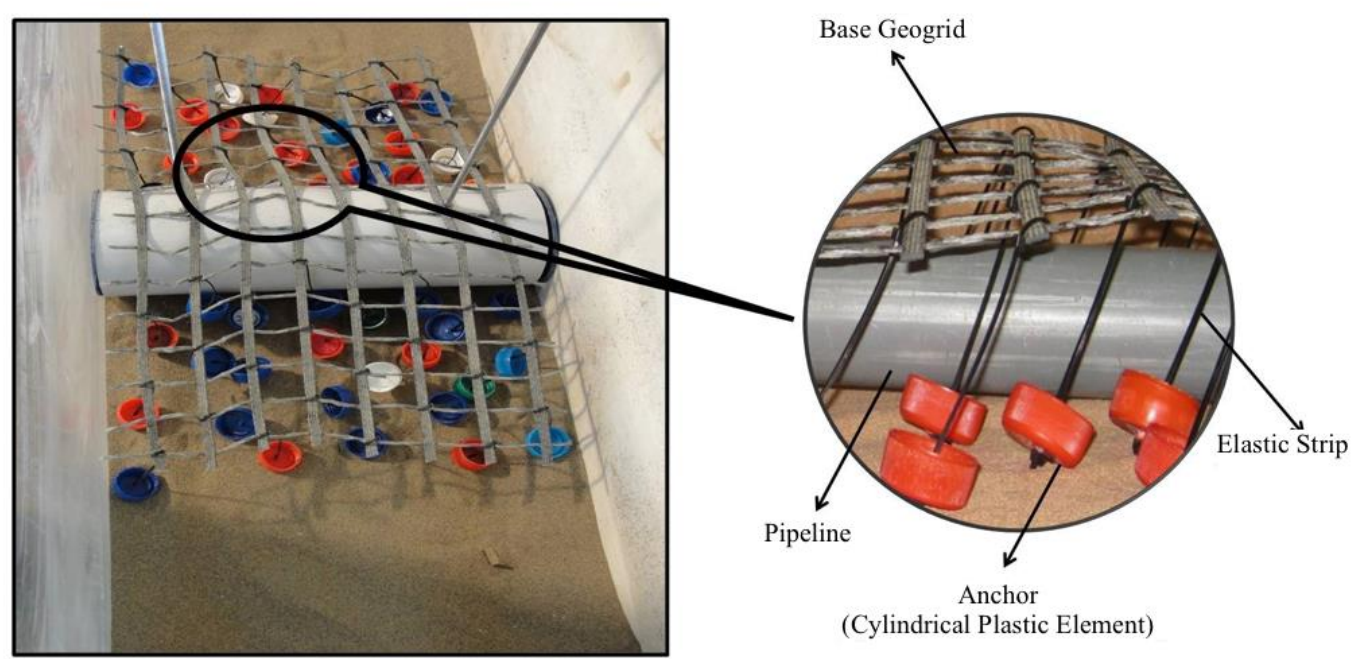




\begin{tabular}{cc} 
Soil angle of internal friction & $28^{\circ}$ \\
Soil cohesion $(\mathrm{kPa})$ & 0 \\
Soil modulus of elasticity $(\mathrm{kPa})$ & 7800 \\
Poisson's ratio & 0.3 \\
Soil unit weight $\left(\mathrm{kN} / \mathrm{m}^{3}\right)$ & 14.2 \\
Soil type & sand \\
Soil constitutive model & Mohr-Coulomb \\
Axial stiffness of geogrids $(\mathrm{kN} / \mathrm{m})$ & 28 \\
Axial stiffness of anchors $(\mathrm{kN})$ & 0.08 \\
Pipe diameter (mm) & 50,100 and 200 \\
Length of elastic strips $(\mathrm{mm})$ & 80 \\
Anchor plates diameter $(\mathrm{mm})$ & 30 \\
Horizontal angle of anchors & $45^{\circ}$ \\
\hline
\end{tabular}

\section{Experimental Tests}

In this study, 23 full-scale physical experiments were carried out to investigate the uplift capacity of the pipeline section in the soil. The experiment set up included a cuboid test box and a pulling system that used a pneumatic actuator to apply uplift force to the pipe. The pneumatic speed controller also controled the movement rate of the loading system. The loading rate $0.04 \mathrm{~mm} / \mathrm{s}$ was used in the experiments. To minimize the skin friction between the Plexiglas or steel and the pipe, two pieces of a plastic cap were used as a smooth material on the sides of the pipe.

The dimensions of the chamber used were $1000 \mathrm{~mm}, 1000 \mathrm{~mm}$ and $1000 \mathrm{~mm}$ for length, width and height respectively. Three sides and base of the chamber were made using $25 \mathrm{~mm}$ thick steel plates while the front side was made of $20 \mathrm{~mm}$ thick Plexiglas. A schematic model of the experimental setup is shown in Fig. 3.

Three $1000 \mathrm{~mm}$ long pipe sections each with a different diameter $(50 \mathrm{~mm}, 100 \mathrm{~mm}$, and $200 \mathrm{~mm})$ were used in the experiments. The pipes were simply buried in the sand with embedment ratios $\left(\mathrm{h}^{1} / \mathrm{D}^{2}\right)$ of 1,2 and 3 . Different lengths of geogrid and grid-anchor system (3D, 5D and 8D) were used in this study. In some models, no reinforcing system was used. The burial materials consisted of standard sand with a unit weight of $14.2 \mathrm{kN} / \mathrm{m}^{3}$. Fig. 3-B shows the pullout test using one layer of the grid-anchor system. The material parameters and results of the peak uplift resistance are summarized in Table 2.

The entire simulation process in the DIC/PIV method (including photography process, transfer of the photos to the computer and analysis of the image data) was done automatically. Some malfunction factors such as handshakes in the photography and pressing the camera shutter button were eliminated using EOS-Utility software. EOS-Utility is used in MacOS operating system. A Canon EOS 50D camera with sensitivity of 15.1 megapixels and image clarity of $4852 * 3168$ was used. After the imaging, the digital images were transferred automatically into the computer. The images were then processed using the image processing software geoPIV and MATLAB.

In all of these tests, attempts were made to have a specific position for the camera and a constant distance between the simulator box and camera. Other effective parameters in photography like camera setting and ambient light were same in all of the tests. To remove the negative effects of ambient light on the resulting image and to prevent errors caused by accidental lighting change, two 1000 watt projectors were placed on either side of the camera. Fig. 4 shows the type of camera used and displays how the photography was done. About 300 shots were taken in each test and photos were taken in 3-second intervals.

\footnotetext{
${ }^{1}$ Burial depth of pipe

${ }^{2}$ Pipe diameter
} 


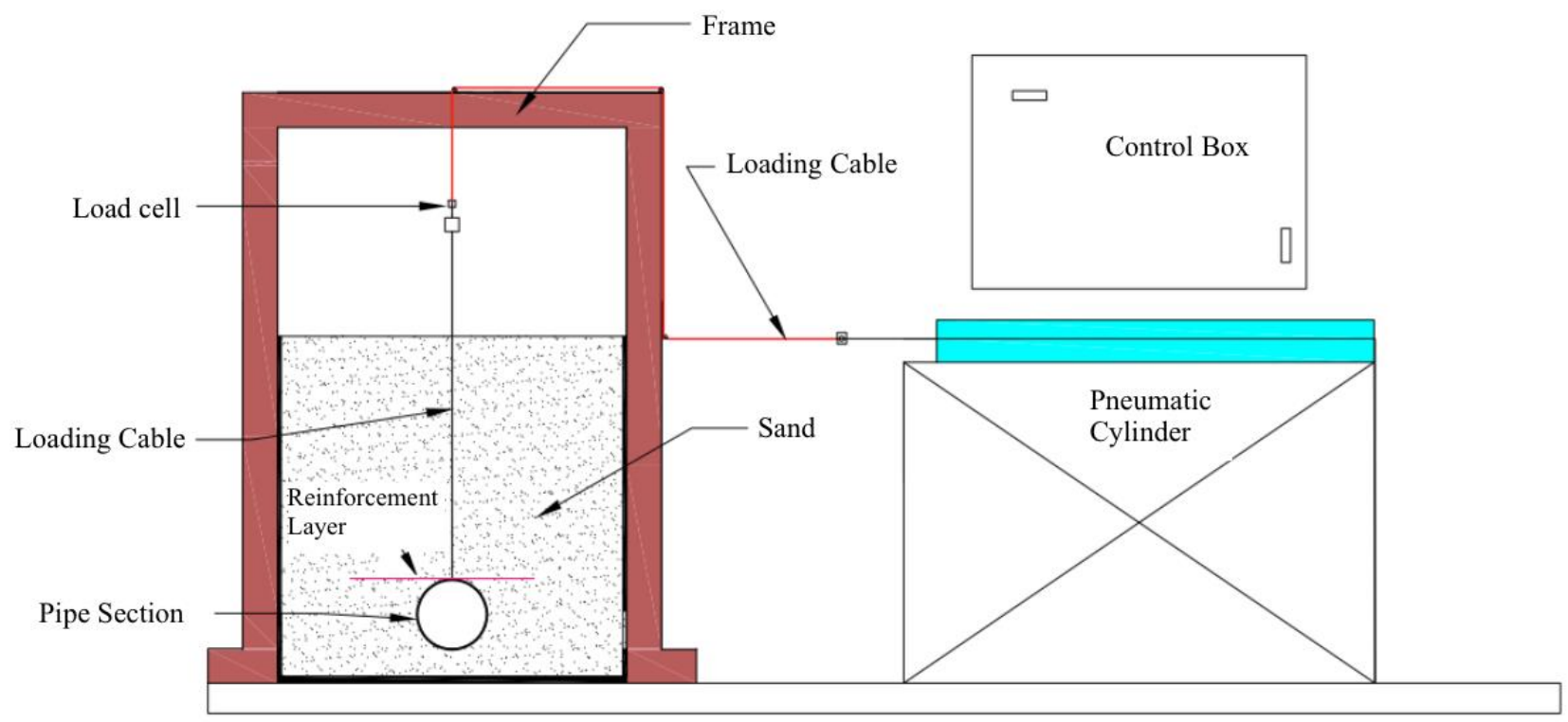

A. Schematic model of the experimental setup

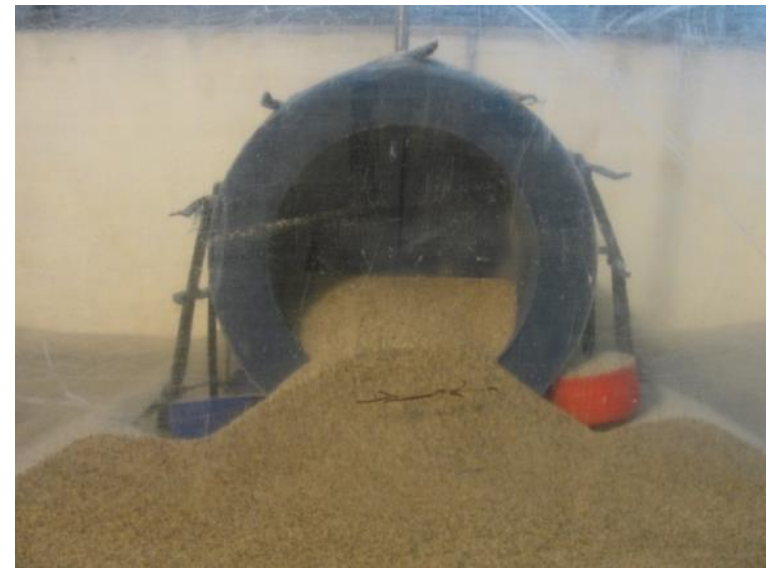

B. Uplift test with one layer of the grid-anchor system in the simulator box

Fig. 3. Experimental setup and reinforced pipe 


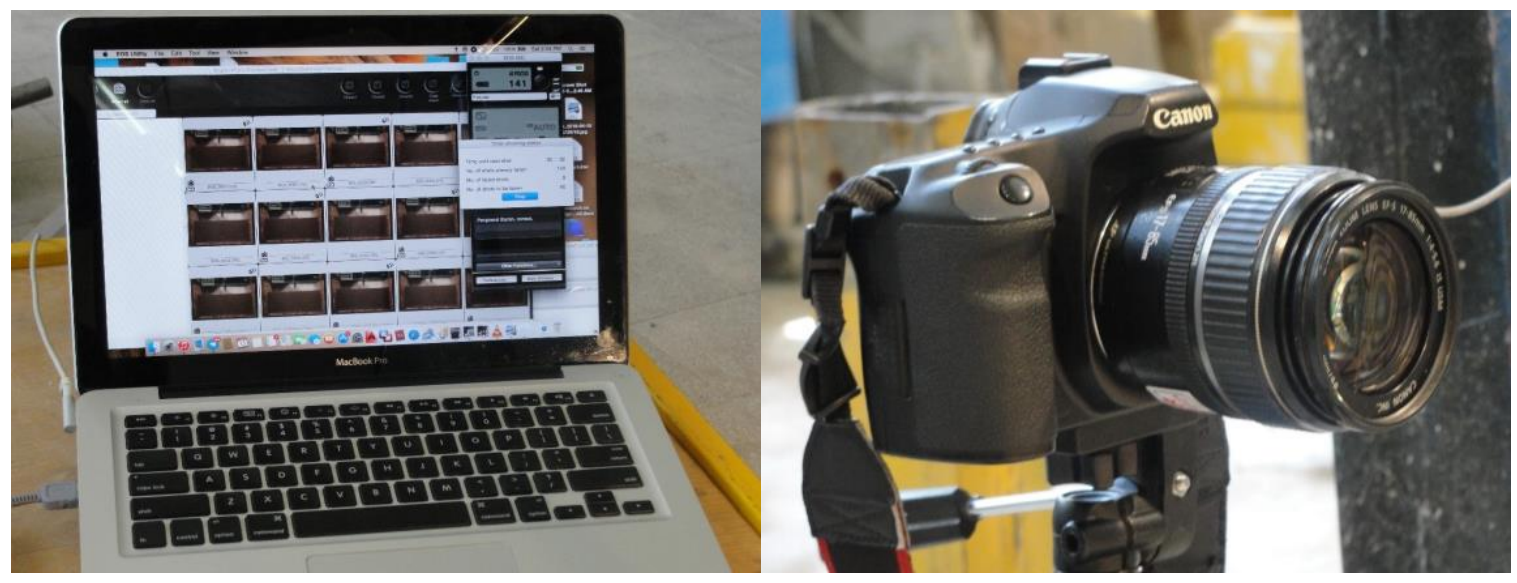

Fig. 4. Camera and photography process

\section{Numerical And Digital Image Analysis}

In this study the finite difference code "FLAC-3D" was used for modeling uplift capacity of buried pipelines in sand reinforced with grid-anchor and geogrid. The effects of the most influencing parameters including the pipe diameter (D), width of reinforced layers (b), number of reinforced layers $(\mathrm{N})$ burial depth of the reinforcement layers and anchors and stiffness of the reinforcement on the uplift resistance of the pipe were investigated. For soil modeling, the Mohr-Coulomb constitutive model was used due to its simplicity and ease of use. The parameters used in the analysis are summarized in Table 1.

The geogrid layers were free in three dimensions. The geogrid behavior was considered orthotropic and linear elastic without failure limit. In addition the geogrid was modeled as a flexible membrane having significant shear interaction with the soil like geotextiles (Itasca, 2012).

DIC/PIV uses the pixel intensity values to compute the incremental propagation of accuracy. This process can be explained by considering what a digital image represents. Each of the images that were taken in the uplift test process differs from others. The differences indicate displacement of the soil grains and buried pipe that can be measured and analyzed with MATLAB and geoPIV. The displacement vectors of soil and distribution of shear strains in the soil are presented in Figs. 911.

The grid-anchors were modeled as cable element which is one of FLAC's structural elements. Each structural element was defined by its geometrical properties, and was considered to have elastic, perfectly plastic behavior. Also, each cable had its own local coordinate system, as shown in Fig. 1. Fig. 5 shows the grid-anchor idealization and anchor coordinate system defined by two nodal point location. Fig. 6 shows the finite difference mesh employed for the analysis.

Geogrids with width of 8D ( 8 times the Diameter of the pipe) were used in the models to avoid boundary effects; as primary models affirmed that, with width greater than $8 \mathrm{D}$, boundary conditions were insignificant. A total of 23 models were analyzed to determine the uplift resistance of buried pipes and the mechanism of failure involved. The models were 3D, 5D and $8 \mathrm{D}$ in the reinforced by geogrid and grid-anchor sand. Unreinforced systems were also used to compare the results. 


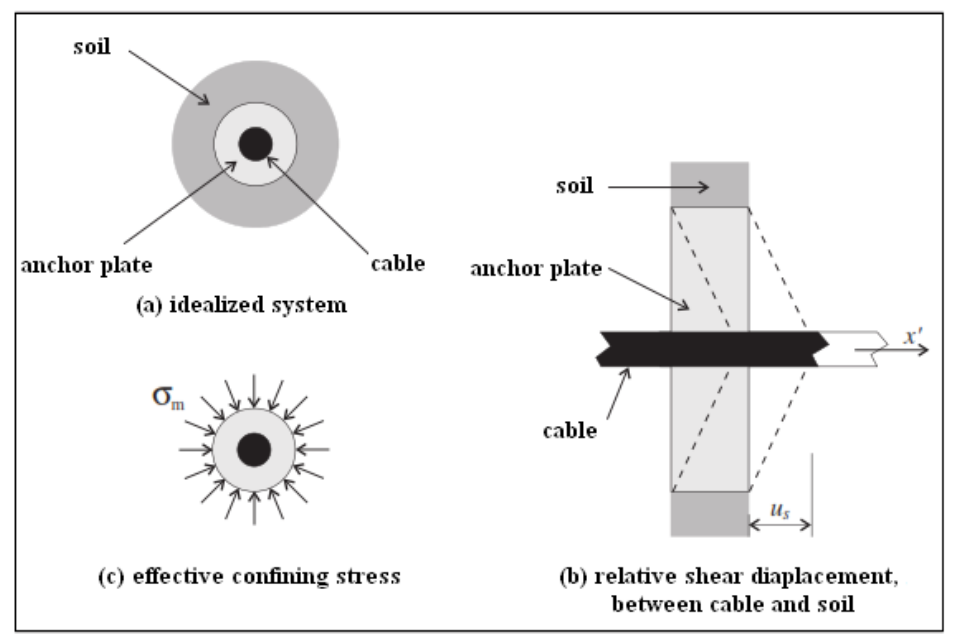

Fig. 5. Idealization of the grid-anchor system (Itasca, 2012)

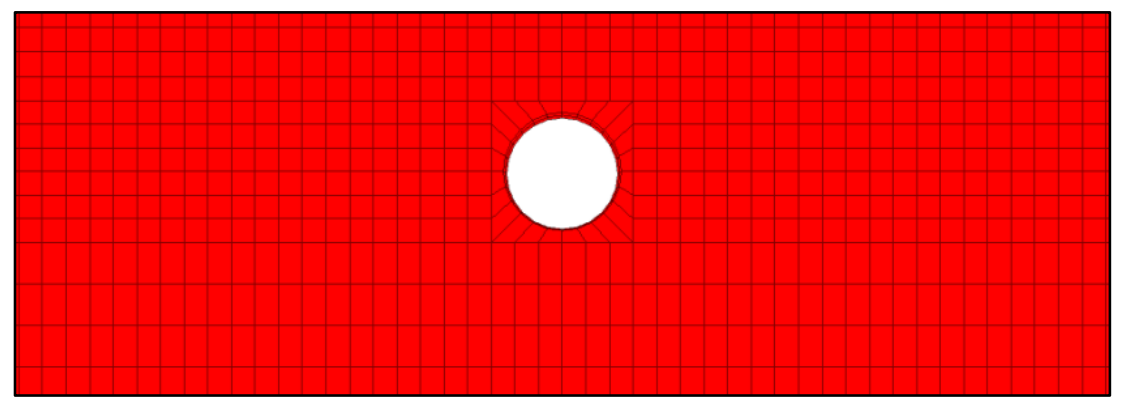

Fig. 6. 3D mesh at section plane across the model center

\section{Verification of Effectiveness of the Grid-Anchor System}

The laboratory tests were conduscted to evaluate the effects of soil reinforcement on uplift resistance of the buried pipelines. These tests were also modeled numerically in "FLAC-3D" (version 5.0). The experimental results were used to validate the numerical model. Table 2 shows the model parameters used and a comparison of the values of peak uplift resistance obtained from the experimental results tests and numerical simulations.

In general, the results show the effectiveness of the geogrid and grid-anchor systems in increasing the uplift resistance of buried pipelines. Fig. 7 shows a comparison between experimental results obtained with three different widths. The results from the experiments and DIC/PIV analysis clearly show that using the grid-anchor system is more effective in improving the uplift capacity of the pipelines compared to ordinary geogrids. The results also indicate that, in the grid-anchor system the value of peak uplift resistance (PUR) is 2.4 times greater than the ordinary geogrid and 4 times greater than the nonreinforced case.

For the Models $\mathrm{M}_{7}, \mathrm{M}_{8}$ and $\mathrm{M}_{9}$ the measured peak uplift resistance (PUR) from experimental tests was 70, 116 and 286 $\mathrm{N}$, conducted at soil density of $1420 \mathrm{~kg} / \mathrm{m}^{3}$, reinforcement width of $5 \mathrm{D}(\mathrm{b}=250 \mathrm{~mm})$, and burial depth of $1 \mathrm{D}(\mathrm{h}=50 \mathrm{~mm})$. 
Table 2. Results of numerical modeling and experimental tests

\begin{tabular}{|c|c|c|c|c|c|c|c|}
\hline $\begin{array}{l}\text { Test } \\
\text { No. }\end{array}$ & D $(\mathbf{m m})$ & $(\mathbf{h} / \mathbf{D})$ & Rein. system & b (mm) & $\mathbf{N}$ & $\begin{array}{l}\text { Experimental } \\
\text { PUR(N) }\end{array}$ & $\begin{array}{c}\text { Numerical } \\
\operatorname{PUR}(\mathbf{N})\end{array}$ \\
\hline $\mathbf{M}_{1}$ & 50 & 3 & non-reinforced & --- & --- & 325 & 338 \\
\hline $\mathrm{M}_{2}$ & 50 & 3 & geogrid & $5 \mathrm{D}$ & 1 & 450 & 440 \\
\hline $\mathrm{M}_{3}$ & 50 & 3 & grid-anchor & $5 \mathrm{D}$ & 1 & 727 & 679 \\
\hline $\mathrm{M}_{4}$ & 50 & 2 & non-reinforced & --- & --- & 176 & 182 \\
\hline $\mathrm{M}_{5}$ & 50 & 2 & geogrid & $5 \mathrm{D}$ & 1 & 264 & 250 \\
\hline $\mathrm{M}_{6}$ & 50 & 2 & grid-anchor & $5 \mathrm{D}$ & 1 & 575 & 527 \\
\hline $\mathrm{M}_{7}$ & 50 & 1 & non-reinforced & --- & --- & 70 & 77 \\
\hline $\mathrm{M}_{8}$ & 50 & 1 & geogrid & $5 \mathrm{D}$ & 1 & 116 & 110 \\
\hline $\mathrm{M}_{9}$ & 50 & 1 & grid-anchor & $5 \mathrm{D}$ & 1 & 286 & 250 \\
\hline $\mathrm{M}_{10}$ & 50 & 2 & geogrid & $3 \mathrm{D}$ & 1 & 205 & 197 \\
\hline $\mathrm{M}_{11}$ & 50 & 2 & grid-anchor & $3 \mathrm{D}$ & 1 & 380 & 364 \\
\hline $\mathrm{M}_{12}$ & 50 & 2 & geogrid & $8 \mathrm{D}$ & 1 & 293 & 279 \\
\hline $\mathrm{M}_{13}$ & 50 & 2 & grid-anchor & $8 \mathrm{D}$ & 1 & 710 & 675 \\
\hline $\mathrm{M}_{14}$ & 100 & 2 & geogrid & $5 \mathrm{D}$ & 2 & 920 & 927 \\
\hline $\mathbf{M}_{15}$ & 100 & 2 & grid-anchor & $5 \mathrm{D}$ & 2 & 1440 & 1220 \\
\hline $\mathrm{M}_{16}$ & 100 & 2 & geogrid & $5 \mathrm{D}$ & 3 & 965 & 952 \\
\hline $\mathrm{M}_{17}$ & 100 & 2 & grid-anchor & $5 \mathrm{D}$ & 3 & 1520 & 1226 \\
\hline $\mathrm{M}_{18}$ & 100 & 2 & non-reinforced & --- & --- & 708 & 721 \\
\hline $\mathbf{M}_{19}$ & 100 & 2 & geogrid & $5 \mathrm{D}$ & 1 & 912 & 901 \\
\hline $\mathrm{M}_{20}$ & 100 & 2 & grid-anchor & $5 \mathrm{D}$ & 1 & 1395 & 1170 \\
\hline $\mathrm{M}_{21}$ & 200 & 2 & non-reinforced & --- & --- & 3187 & 3218 \\
\hline $\mathrm{M}_{22}$ & 200 & 2 & geogrid & $5 \mathrm{D}$ & 1 & 3513 & 3476 \\
\hline $\mathrm{M}_{23}$ & 200 & 2 & grid-anchor & $5 \mathrm{D}$ & 1 & 5226 & 4628 \\
\hline
\end{tabular}

Fig. 7 shows the efficiency of the grid-anchor system in enhancing the uplift resistance in buried pipelines. Also a ductile post-peak behavior can be inferred in higher uplift resistance. Fig. 8 shows that the uplift resistance in the grid-anchor and geogrid was approximately $308 \%$ and $65 \%$ higher than the non-reinforced loose soil. 


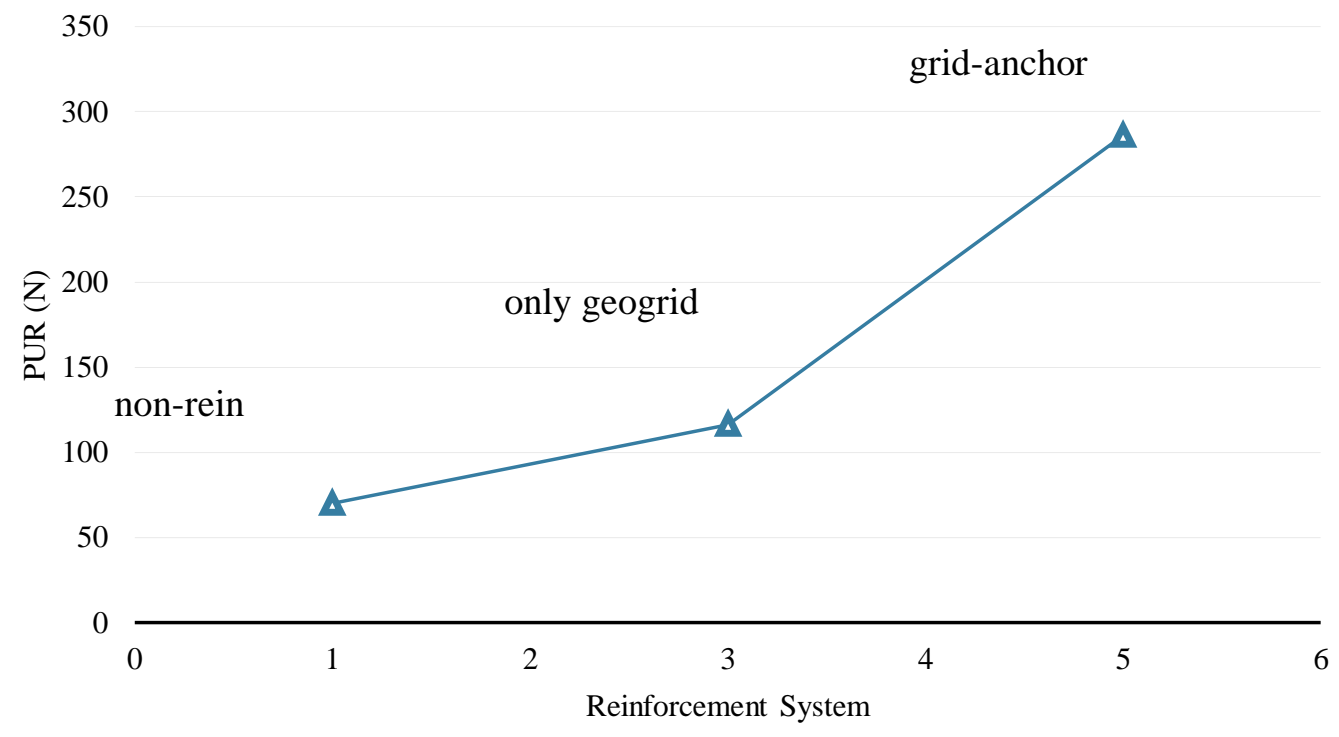

Fig. 7. Experimental peak uplift resistance (PUR) with a selected reinforcing system $(D=50 \mathrm{~mm}, \mathrm{~N}=1, \mathrm{~h} / \mathrm{D}=1, \mathrm{~b}=250 \mathrm{~mm})$

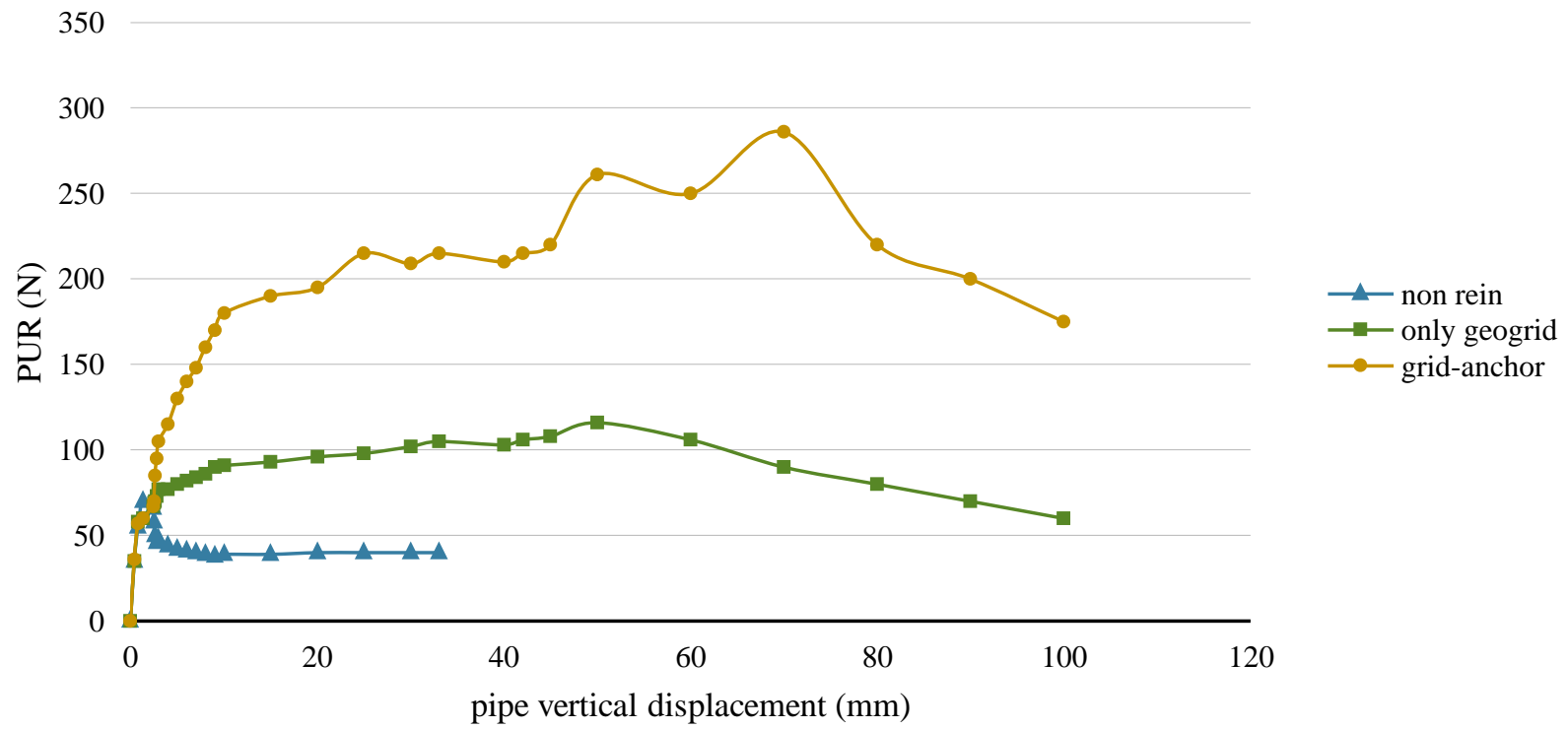

Fig. 8. Uplift force versus pipe vertical displacement curves for models $M 7, M 8$ and $M 9$ obtained from experimental tests $(D=50$ $\mathrm{mm}, \mathrm{N}=1, \mathrm{~h} / \mathrm{D}=1, \mathrm{~b}=250 \mathrm{~mm}$ ) 


\section{Overview of Soil Failure Mechanism Studies}

The DIC/PIV analysis shows that the failure wedge occurs in all cases, but the mode of them is different (see Fig. 9). The distribution of shear strain in the soil caused by buried pipeline after commencement of uplift in the non-reinforced loose sand has simpler mode and displacement vectors of the soil are focused around a small area around and above the pipeline, although in the ordinary mode of geogrid reinforced soil, the failure wedge is different, as shown in Fig. 10 (A and B). The common factor in the formation of the failure wedge is the collapse of the soil surrounding the pipe to fill the void space formed under the geogrid.

Increasing the strength of the soil due to the use of geogrid, causes the formation of horizontal shear strength in the soil mass and extends the effective area of the pipe to the base of the pipe and underneath it, leading to the enlargement of the failure wedge of the soil and thus the mobilization of more forces for the pipeline capacity. In the grid-anchor reinforced system, the failure wedge is totally different which clearly shows the effect of increasing the uplift resistance in grid-anchor reinforced system as shown in Fig. 11 (A and B).This figure shows the amounts of displacement of soil in different cases of the reinforced system and also the increase in the uplift resistance of buried pipeline. The results of the numerical analysis also show that the buried pipelines would fail with a curved shear surface. As shown in Fig. 12 (A, B and C), the failure mechanisms of non-reinforced, reinforced with ordinary geogrid and reinforced with the grid-anchor systems in loose sand are in agreement with the results of the DIC/PIV measurements.

The results of numerical analysis of the uplift failure mechanism show that the buried pipelines would fail with a curved shear surface, as shown in Figs. 9-11. The mechanism of shear failure during uplift for buried pipelines in non-reinforced soil, soil reinforced with ordinary geogrid, and soil reinforced with the grid-anchor system under the same conditions are illustrated in Figs. 9-11. An important factor causing the formation of the curved shaped failure surface would be the collapse of the soil around the pipe to fill in the void space formed near the bottom of the pipe. Figs. 9-11 illustrate different buried pipelines deflection behavior during uplift of the pipelines in non-reinforced soil, and soils reinforced with ordinary geogrid, and grid-anchor systems in loose sand. Figs. 9-11 also indicate that a shear zone is formed during uplift. Along the pipelinesoil interface, this mechanism is illustrated by the movement of the soil particles, which follows the pipeline during uplift and also this shear zone comprises displaced soil particles, hence it is considered to be influential in increasing the uplift capacity. The outfitted tension trend in the reinforcement allows the grid-anchor and geogrid to resist the build up of horizontal shear stresses in the sand mass inside the loaded zone, and moves them beside the stable layers of sand, which leads to a wider and deeper failure zone. 


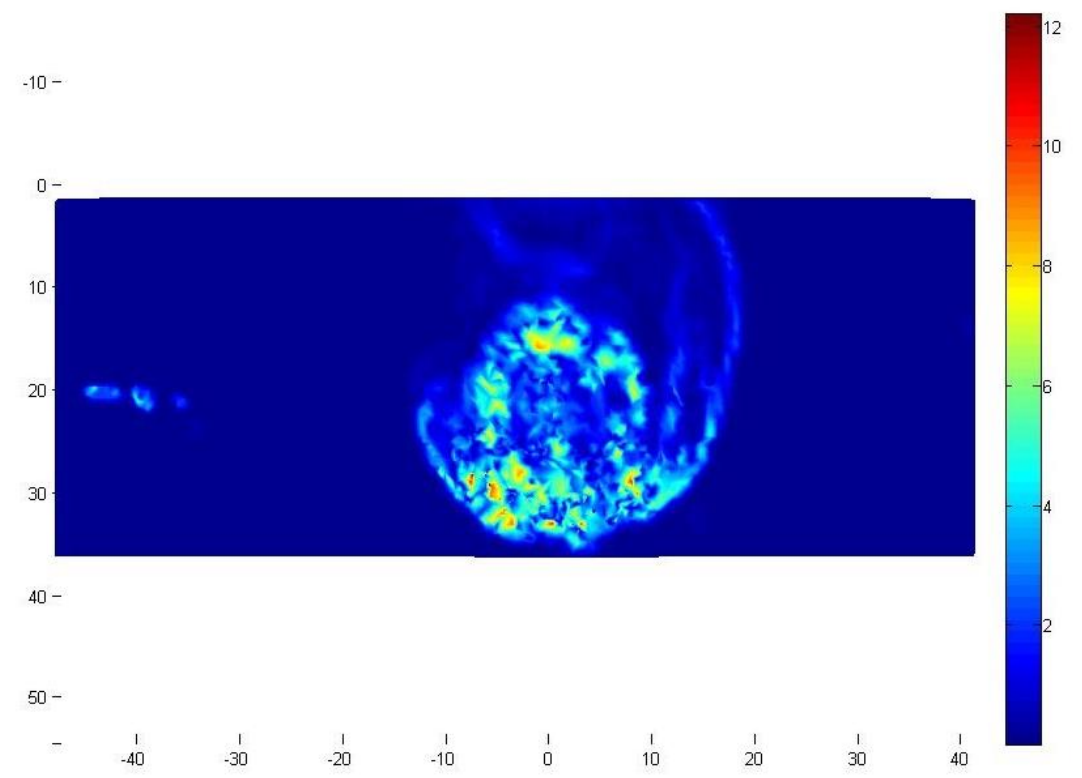

\section{A. Distribution of soil shear strain}

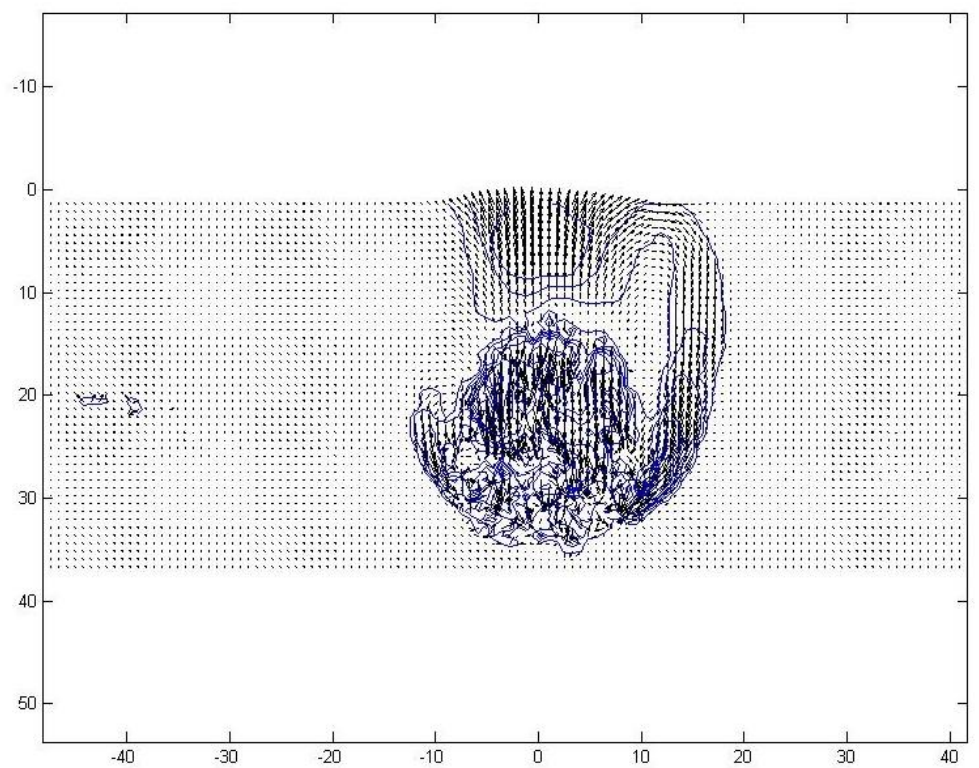

B. Displacement vectors of soil

Fig. 9. Mechanism of soil failure caused by buried pipe uplift pressure in non-reinforced loose sand 


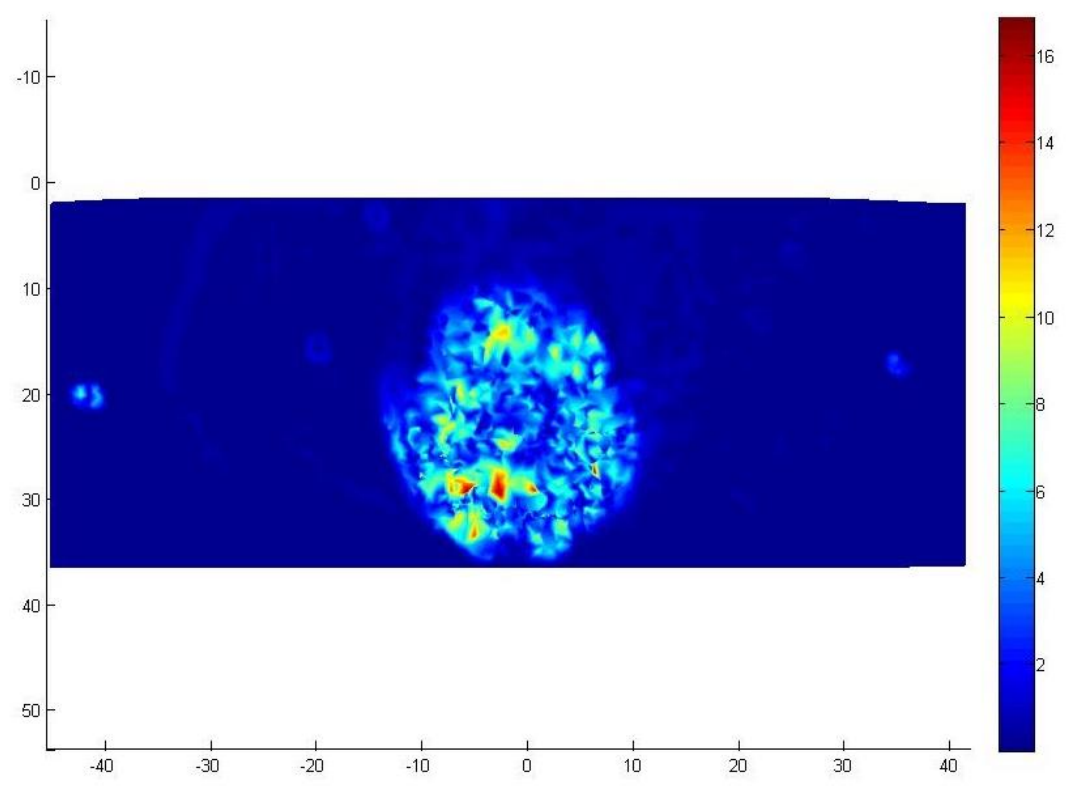

A. Distribution of soil shear strain

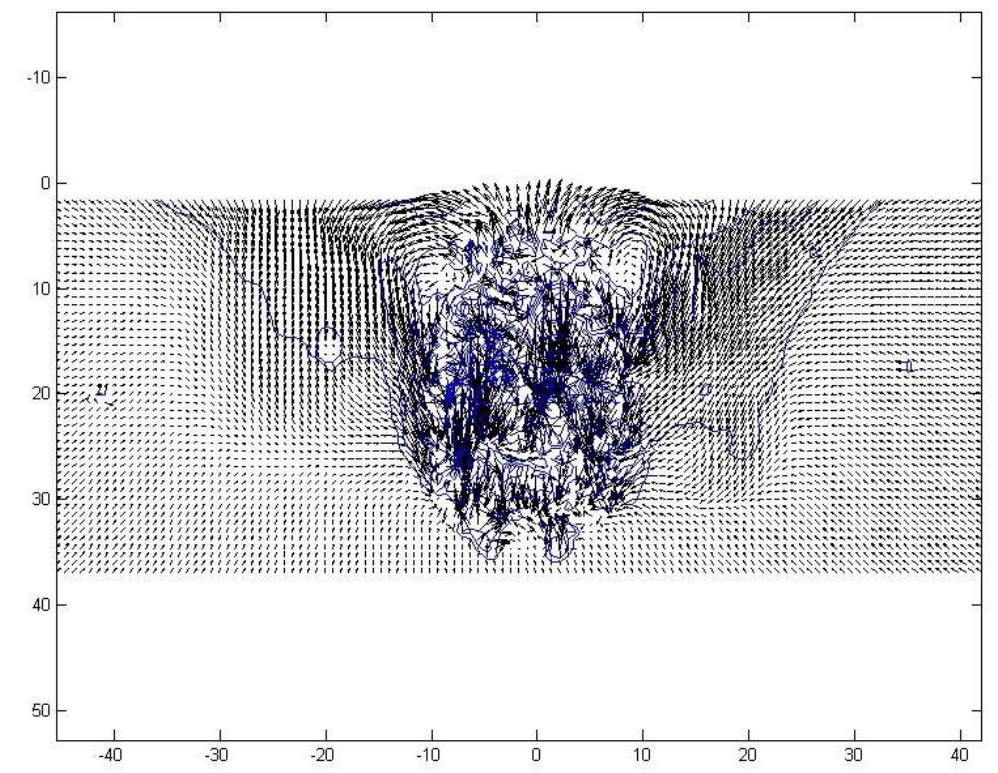

B. Displacement vectors of soil

Fig. 10. Mechanism of soil failure caused by buried pipe uplift pressure in ordinary reinforced loose sand 


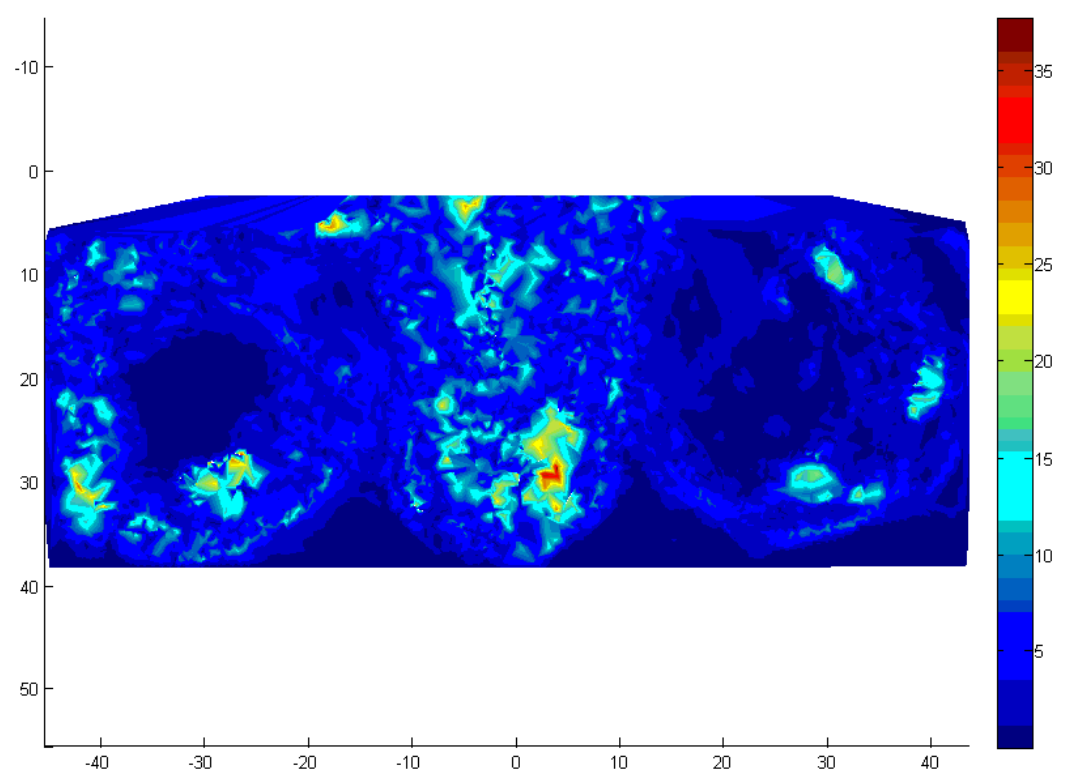

A. Distribution of soil shear strain

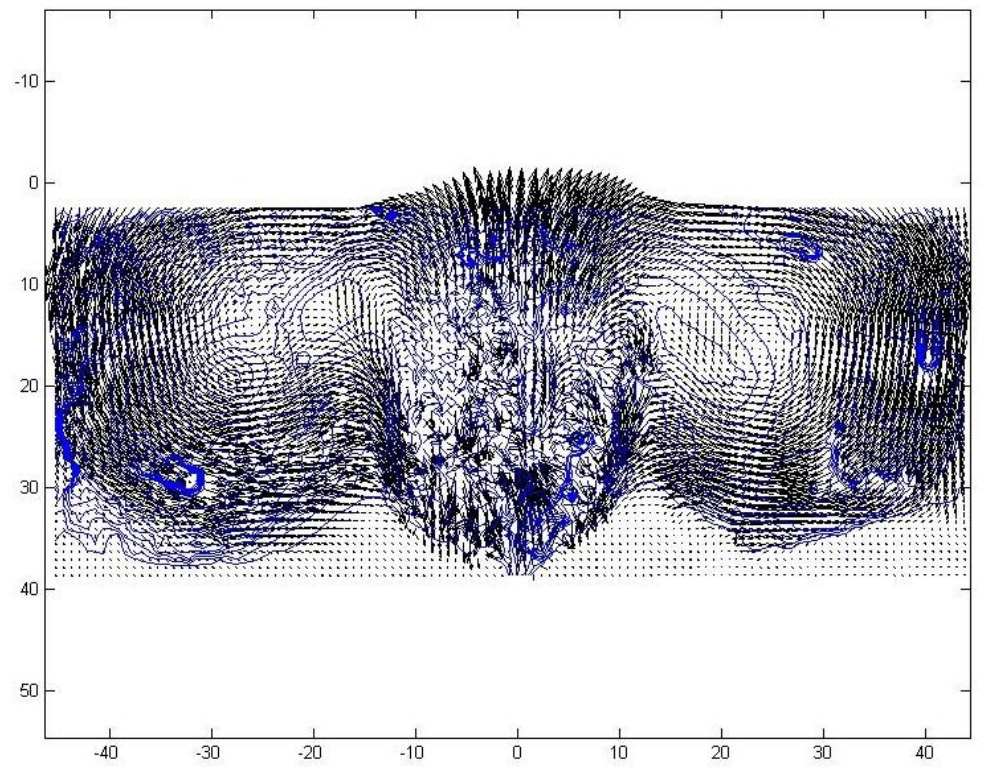

B. Displacement vectors of soil

Fig. 11. Mechanism of soil failure caused by buried pipe uplift pressure in grid-anchor reinforced loose sand 


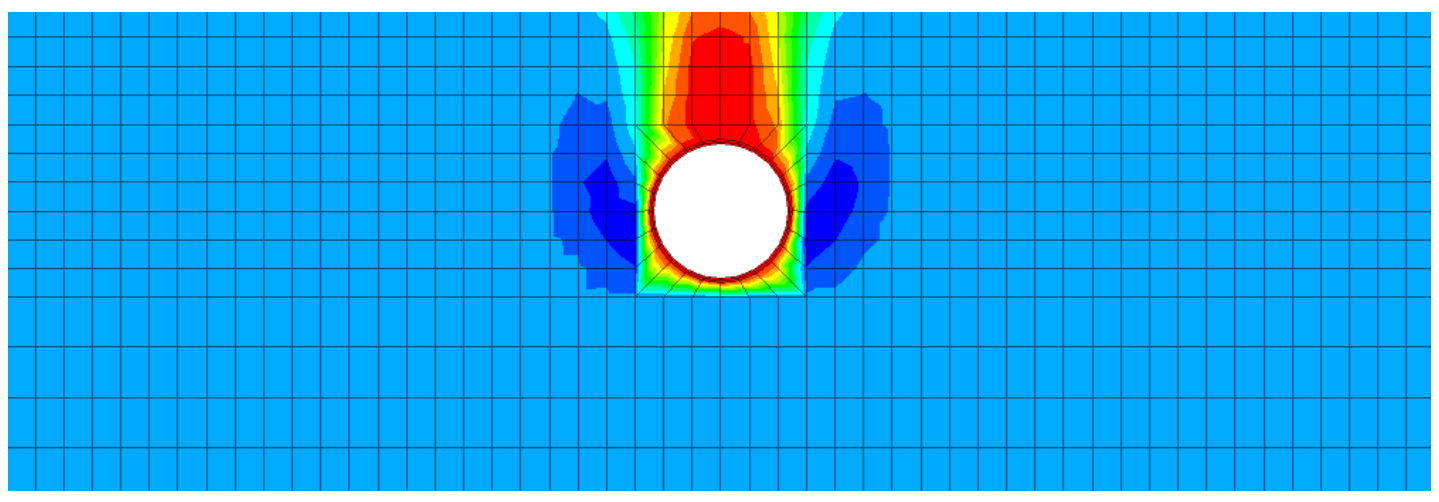

A. non-reinforced case

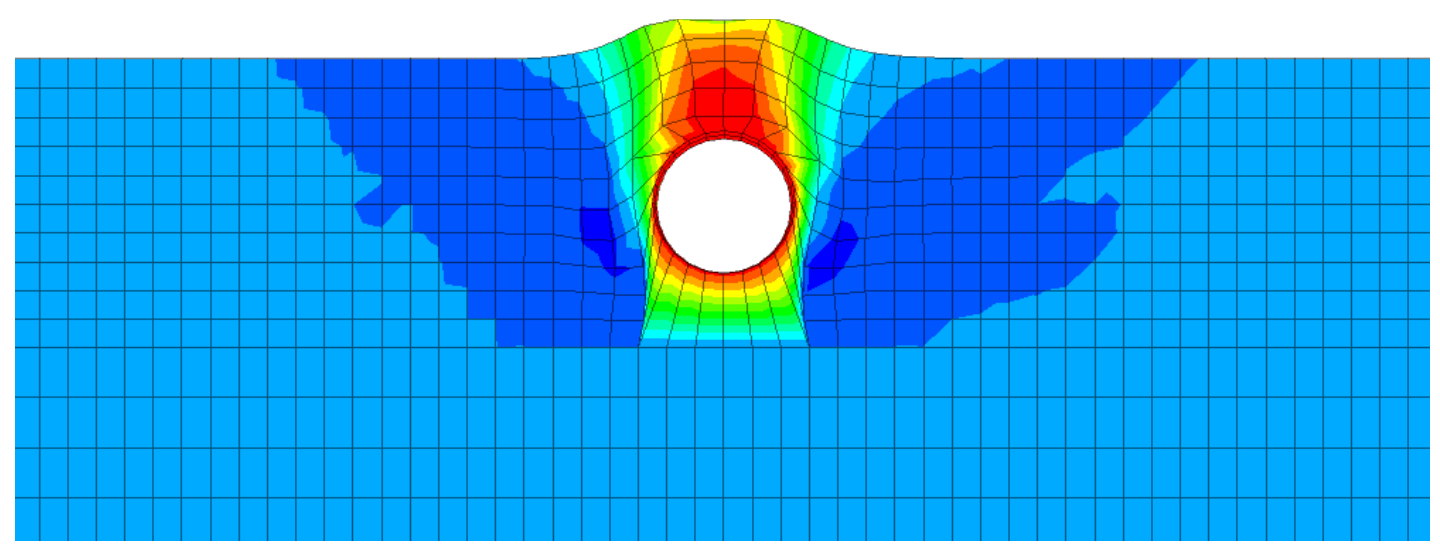

B. geogrid-reinforced case

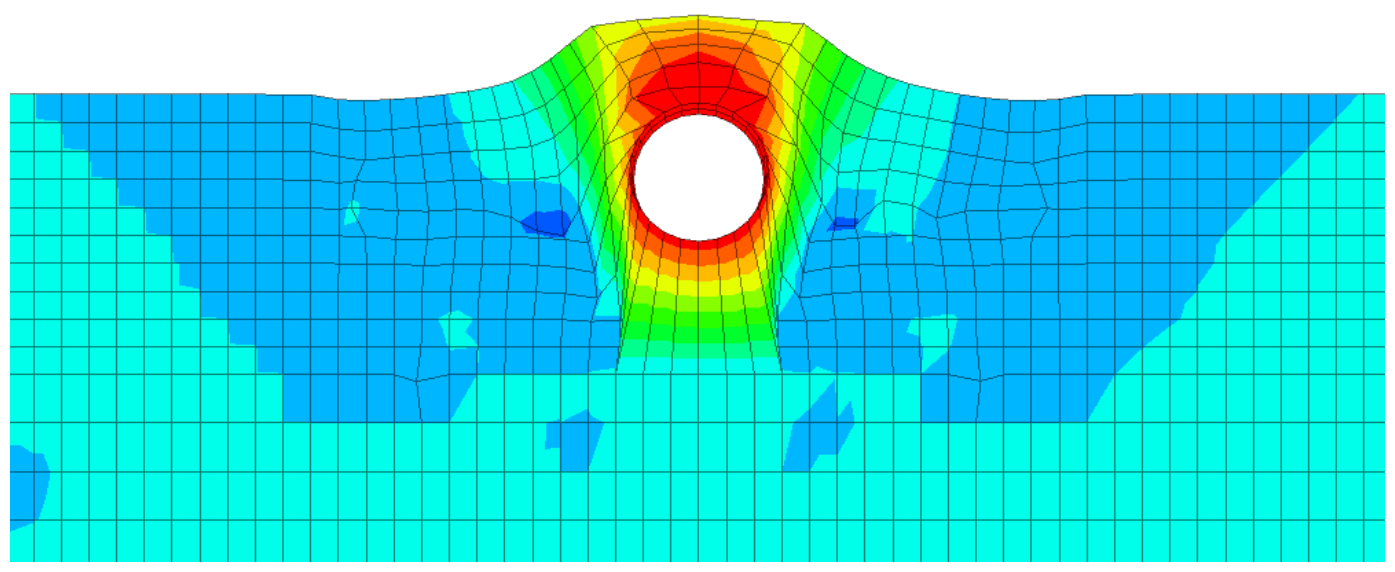

C. grid-anchor reinforced case

Fig. 12. Distribution of sand after the commencement of uplift in loose sand 


\section{Parametric Studies}

In this section, a parametric study is carried out to analyze the effects of different parameters on the uplift capacity of the pipelines in non-reinforced, geogrid-reinforced and grid-anchor-reinforced soils. In particular, the influence of number of reinforcement layers (N), pipe diameter (D), width of reinforcement layer (b) and pipe's embedment ratio (h/D) is studied.

\section{Influence of number of reinforcement layers $(\mathrm{N})$}

Six tests $\left(\mathrm{M}_{6}, \mathrm{M}_{7}, \mathrm{M}_{14}\right.$ to $\left.\mathrm{M}_{17}\right)$ were carried out to study the effects of changing the number of grid-anchor and geogrid inclusions on the behavior of the pipeline with a diameter of $100 \mathrm{~mm}$ and embedment ratio of $2(\mathrm{~h}=200 \mathrm{~mm})$ in loose sand. The experimental results show that the value of PUR does not change significantly with the number of reinforcement layers, N. Fig. 13 clearly shows that the number of reinforcement layers has no notable effect on the pipe uplift resistance. Since one reinforcement layer and multiple layers have the same failure zone angle, it would be economical to use one reinforcement layer. These results are in good agreement with those reported by Niroumand et al. (2013).

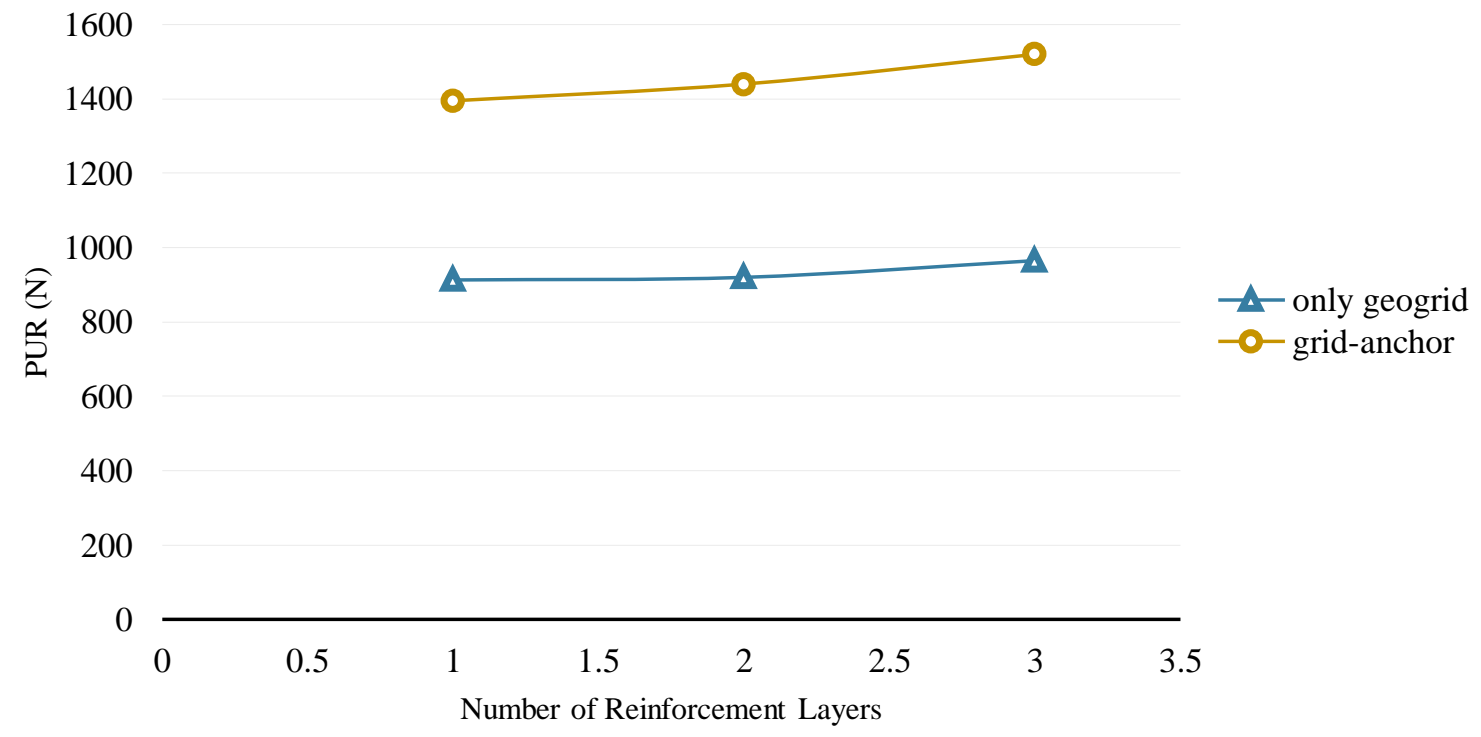

Fig. 13. Variation of PUR with number of reinforcement layers $(\mathrm{N})$ for pipelines in loose sand

\section{Influence of pipe diameter on the pipeline uplift capacity}

Nine tests $\left(\mathrm{M}_{4}, \mathrm{M}_{5}, \mathrm{M}_{6}, \mathrm{M}_{18}\right.$, to $\left.\mathrm{M}_{23}\right)$ were conducted to study the effects of diameter of the pipeline on the uplift capacity. The results (Fig. 14) show that increasing the diameter of the pipeline increases the uplift capacity. For the pipes with a diameter of $50 \mathrm{~mm}$, the values of the uplift resistance for the soils with geogrid and with grid-anchor were $50 \%$ and $226 \%$ higher than the non-reinforced soil. The effectiveness of reinforcement in increasing the uplift resistance of pipelines decreases with increasing the pipe diameter. For the pipe with $100 \mathrm{~mm}$ diameter, these values were approximately $29 \%$ and $97 \%$, and for the pipe with $200 \mathrm{~mm}$ diameter, these values were about $10 \%$ and $64 \%$. Therefore, by increasing the pipe diameter the efficiency of reinforcement layer inclusion will be lower. 


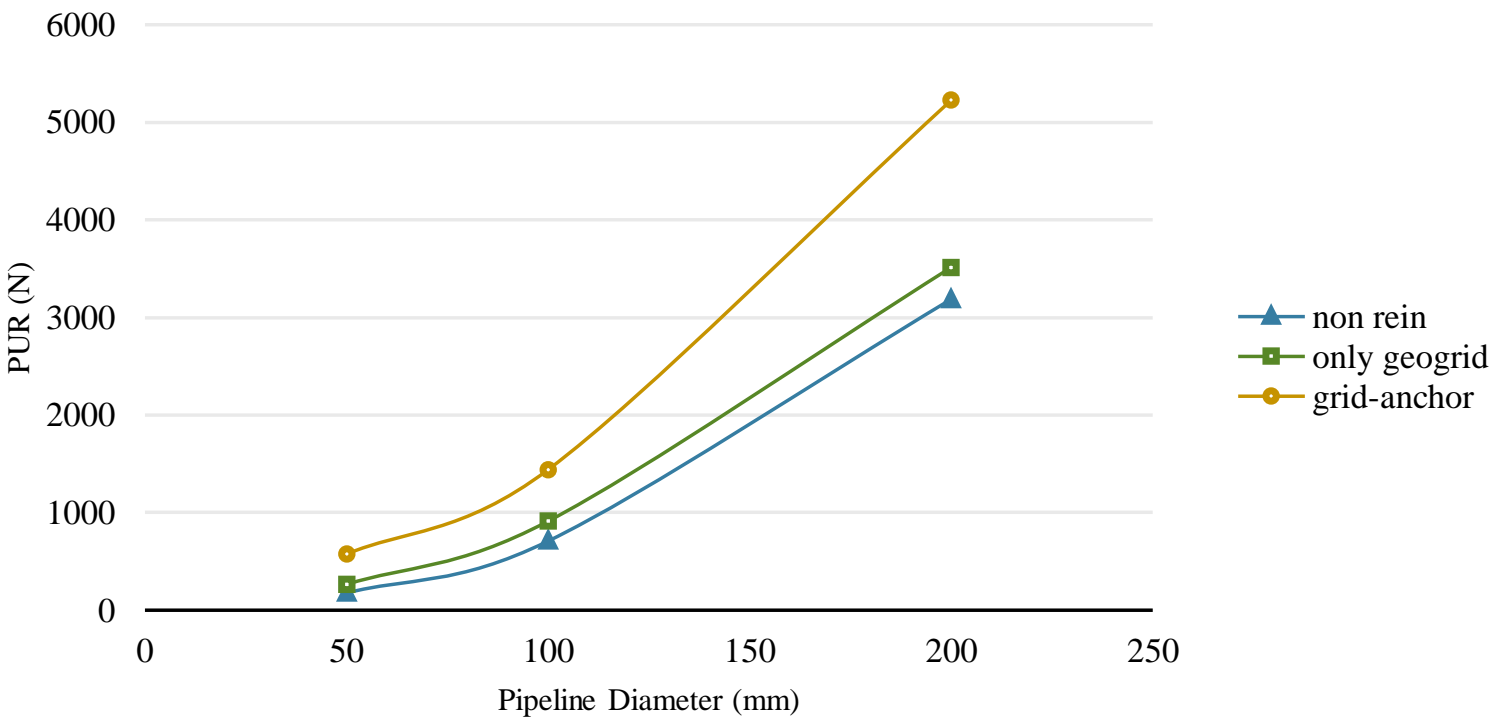

Fig. 14. Variation of PUR with pipeline diameter in loose sand

\section{Influence of pipe's embedment ratio (h/D) on the uplift capacity in dry sand}

In Tests $\mathrm{M}_{1}$ to $\mathrm{M}_{9}$, a pipe with a diameter of $50 \mathrm{~mm}$ was tested in a soil with density of $1420 \mathrm{~kg} / \mathrm{m}^{3}$, reinforcement width of $5 \mathrm{D}(\mathrm{b}=250 \mathrm{~mm})$ and burial depths of $1 \mathrm{D}-3 \mathrm{D}(\mathrm{h}=50-150 \mathrm{~mm})$. The results show that the embedment ratio has a direct relationship with peak uplift resistance (PUR). The PUR of the pipelines buried in non-reinforced soil were 325,176 and 70 $\mathrm{N}$ at h/D of 3, 2, and 1, respectively (Fig. 15). The values of PUR for the pipelines buried in sand reinforced with geogrid were 450, 264 and $116 \mathrm{~N}$ at h/D of 3, 2 and 1 respectively. The corresponding values of PUR for the case of soil reinforced with the grid-anchor system were 727,575 and $286 \mathrm{~N}$ respectively. The results show that, in this reinforced system, the increase in the uplift resistance in tests with an embedment ratio of 1 was approximately $308 \%$, in the test with embedment ratio of 2 it was roughly $226 \%$, and in the test with embedment ratio of 3 it was approximately $123 \%$. It can be concluded that the efficiency of this reinforced system in lower embedment ratios is more than the higher embedment ratios.

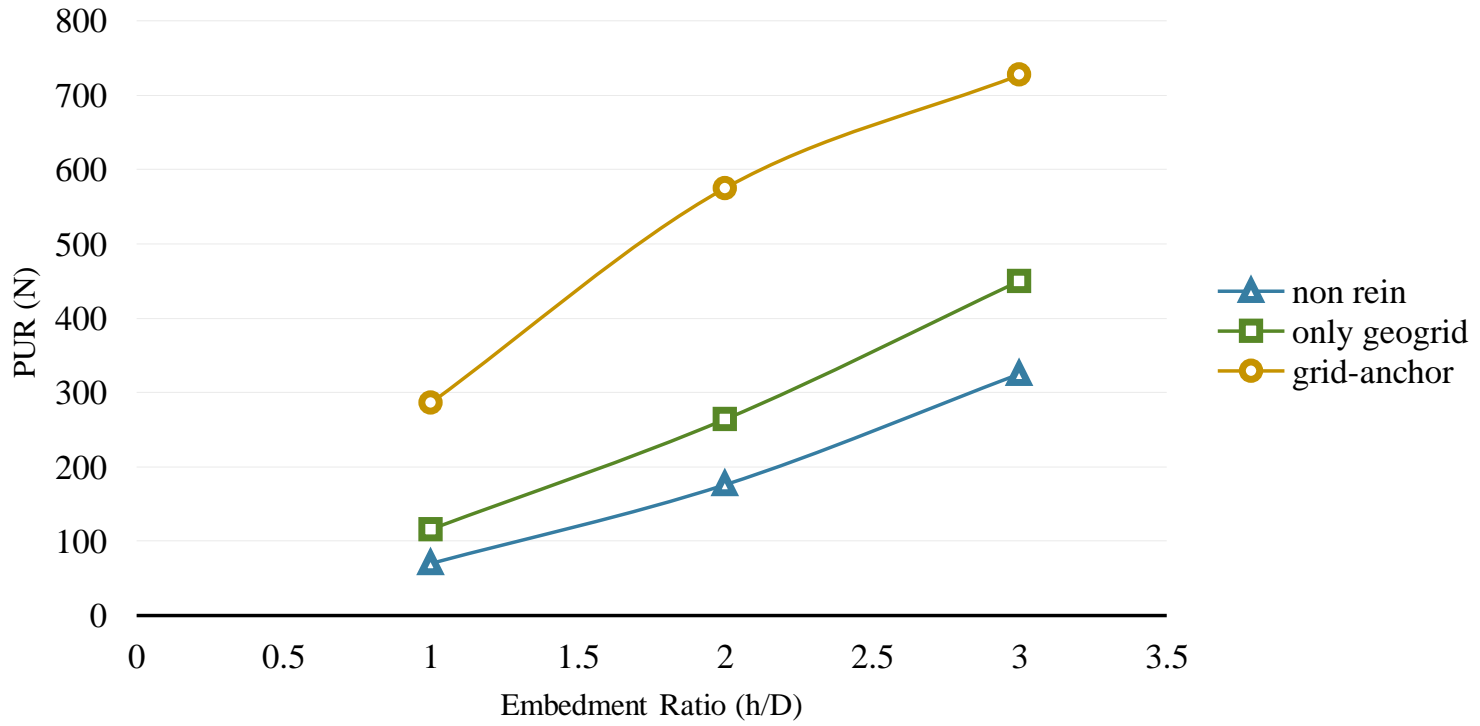

Fig. 15. Variation of PUR with embedment ratio (h/D) for buried pipelines in loose sand 


\section{Influence of geogrid and anchors stiffness on the pipeline uplift capacity}

Based on the experimental tests and the numerical analysis, stiffness of geogrid is not very effective in increasing the uplift capacity of pipelines (as shown in Fig. 16). The results show that increasing the axial stiffness of the reinforcement beyond $6 \mathrm{kN} / \mathrm{m}$ would not result in a remarkable increase in the peak uplift resistance for a single-layer reinforcement.

Fig. 17 shows typical results of variation of peak uplift resistance with the anchor stiffness for single layer reinforcement. In the case of the fixed-end anchor which is a two-node cable element with a constant stiffness, the axial force of the anchors varied from 0 to $8 \mathrm{~N}$. Therefore, as in the case of the geogrid, the application of high stiffness anchors is not necessary for increasing the uplift capacity of pipelines.

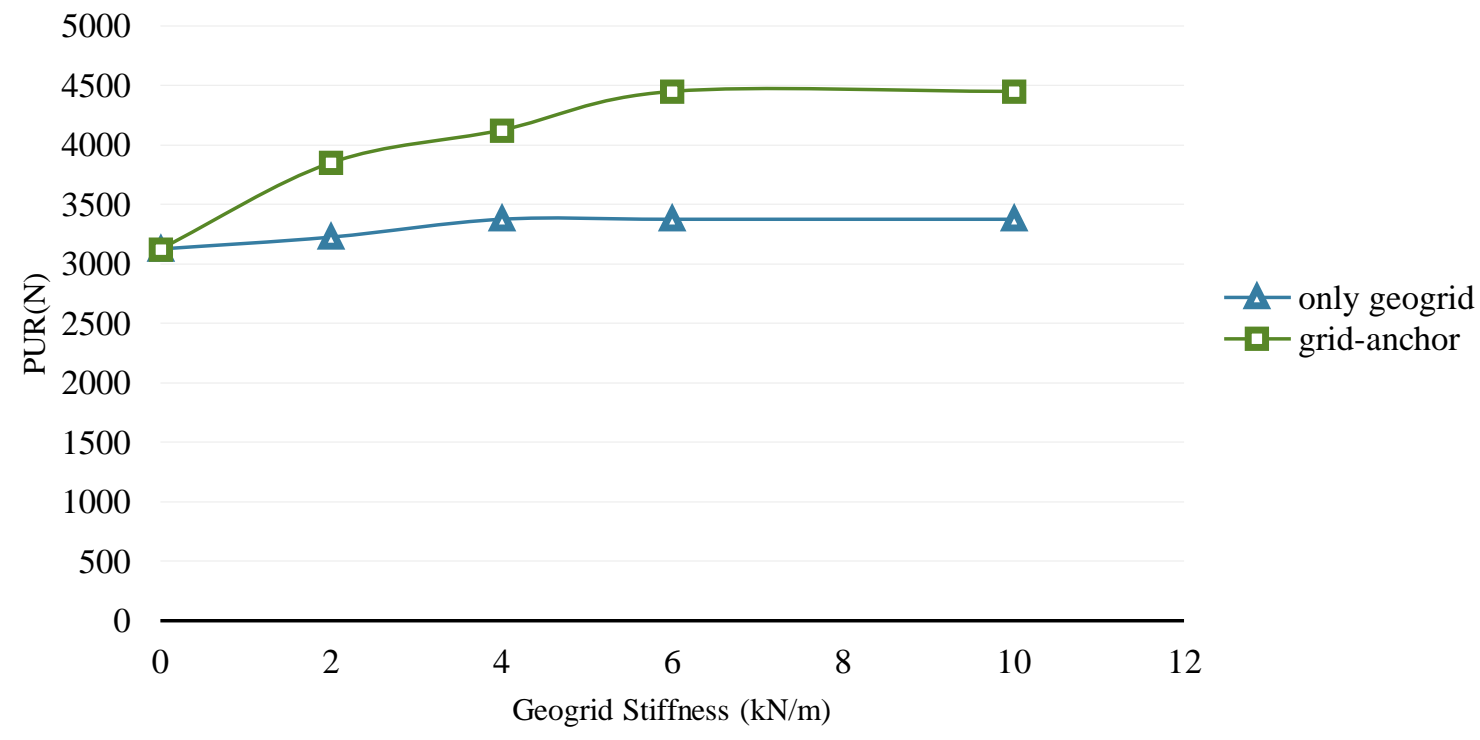

Fig. 16. Variation of PUR with geogrid stiffness $(D=200 \mathrm{~mm}, \mathrm{~N}=1, \mathrm{~h} / \mathrm{D}=2, \mathrm{~b}=5 \mathrm{D})$

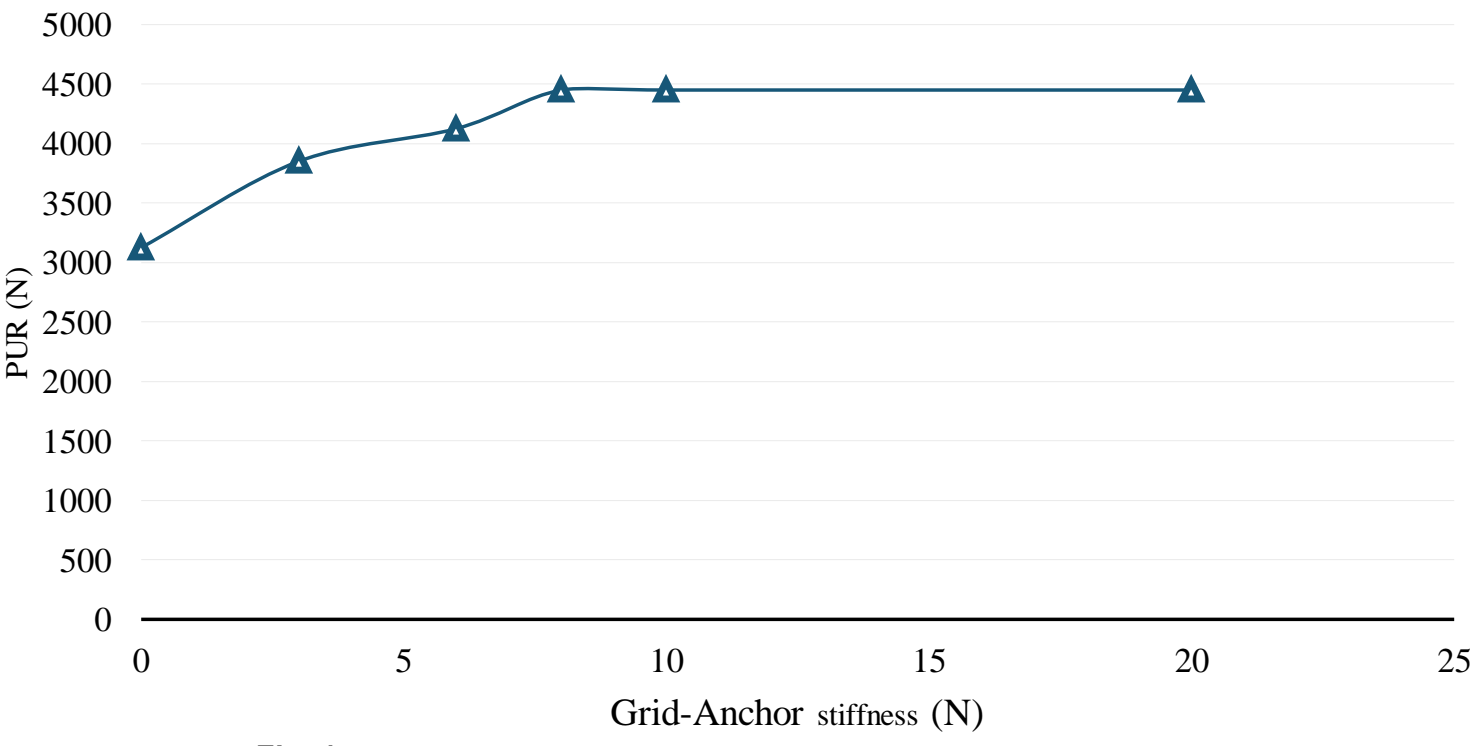

Fig. 17. Variation of PUR with grid-anchor stiffness $(D=200 \mathrm{~mm}, \mathrm{~N}=1, \mathrm{~h} / \mathrm{D}=2, \mathrm{~b}=5 \mathrm{D})$ 


\section{Influence of width of reinforcement layer on the uplift capacity in dry sand}

In test series $\mathrm{M}_{5}, \mathrm{M}_{6}, \mathrm{M}_{10}, \mathrm{M}_{11}, \mathrm{M}_{12}$, and $\mathrm{M}_{13}$, reinforcement layers with widths $3 \mathrm{D}, 5 \mathrm{D}$ and $8 \mathrm{D}$ were used with a pipe diameter (D) of $50 \mathrm{~mm}$, soil density of $1420 \mathrm{~kg} / \mathrm{m}^{3}$ and burial depth of 2D. The results (Fig. 18) show that the peak uplift resistance for the soil reinforced with geogrid, were 205, 286 and 293 for reinforcement widths of 3D, 5D and 8D respectively. The corresponding values of PUR for the soil reinforced with the grid-anchor system with similar soil conditions were 380,575 and $710 \mathrm{~N}$ respectively. The results indicate that increasing reinforcement width can considerably increase the PUR. The PUR increased more rapidly as the reinforcement width increased from 3D to 5D and the optimum ratio of $\mathrm{b} / \mathrm{D}$ was about 5 .

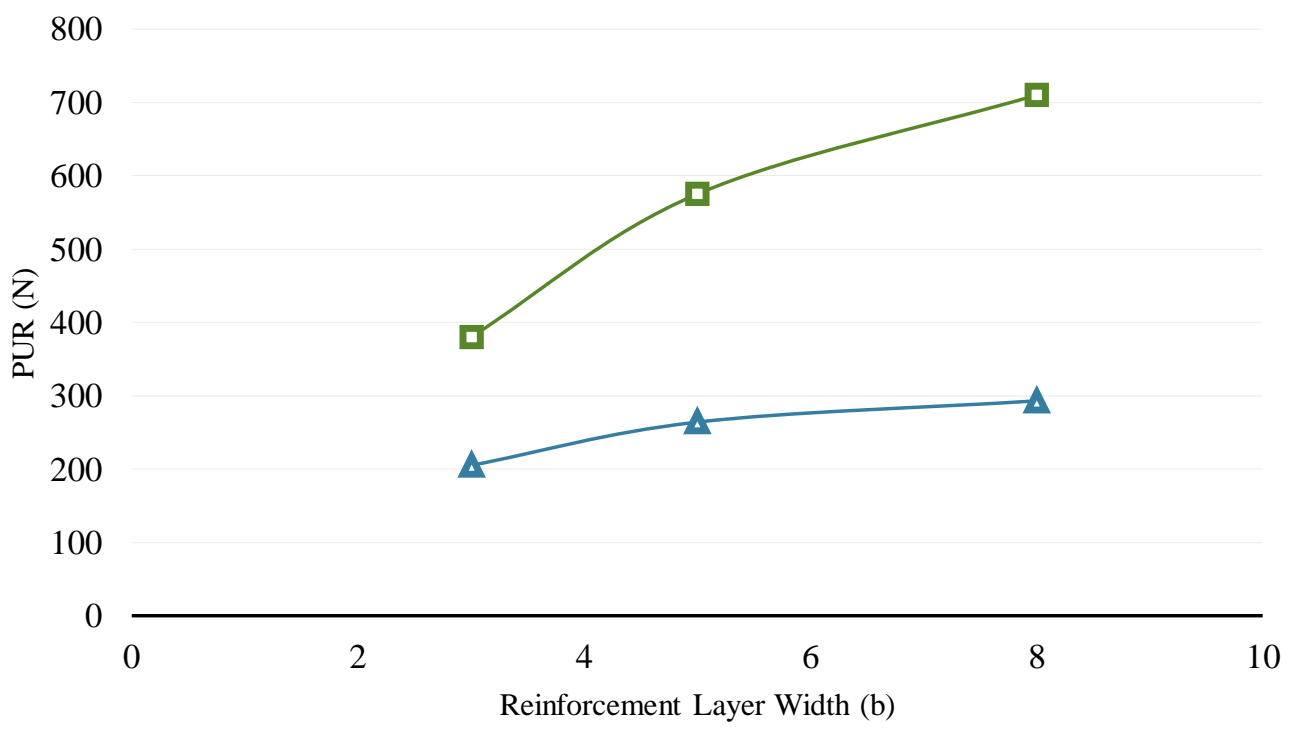

Fig. 18. Variation of PUR with reinforcement width (b) for pipelines in loose dry sand

\section{Conclusions}

A comprehensive program of laboratory experiments was designed and carried out to study the behavior of buried pipelines in loose sand. 23 laboratory tests were carried out to obtain the maximum uplift resistance of pipeline under different conditions. The results of the Digital Image Correlation and Particle Image Velocimetry (DIC/PIV) analysis, show that there is a reasonably good agreement between the experimental tests and numerical analysis results. The PIV method can be very useful in measuring variations of soil deformation in the tests and can speed up the measurement process in the experiments.

The grid-anchor system was presented as an efficient reinforcing method for improving uplift resistance of buried pipelines. This system offers greater resistance against the upward movement of buried pipes compared with conventional geogrid system. The effects of different parameters of the reinforcement system such as the number of reinforcement layers, pipe diameter, embedment ratio of pipeline, stiffness, and width of the reinforcement layer on the uplift resistance of pipelines were investigated.

The experiments were also simulated numerically using "FLAC-3D" (version 5.0) and the results were compared with the experiments results. It was shown that the experimental results are generally in good agreement with the numerical results. The following conclusions can de drawn from the results of this study:

- Using the grid-anchor system is more effective in increasing the uplift resistance than the conventional geogrid reinforcement system.

- The Digital Image Correlation with Particle Image Velocimetry (DIC/PIV) analysis is a suitable method for small scale measurements in geotechnical engineering, like monitoring sand displacements. It has a good accuracy and can reduce the time and cost of experimental tests and speed up the tests.

- Under similar conditions, using the grid-anchor system provides more uplift resistance than the geogrid system. Therefore, the grid-anchor system would be economical and could reduce the pipe coverage depth and excavation costs in the installation of buried pipelines compared to other methods. This system of reinforcement, increases the uplift capacity up to 4 times greater than non-reinforced sand and 2.4 times greater than conventional geogrid reinforced sand. 
- Experimental tests show that the grid-anchor system causes increase the horizontal shear strength in the soil mass and extends the effective area of the pipe to the base of the pipe and underneath it, leading to the enlargement of the failure wedge of the soil and thus the mobilization of more forces for the pipeline capacity.

- One layer of reinforcement over the pipeline is more effective than using multiple layers and increasing the pipe diameter decreases the efficiency of reinforcement layer.

- Increasing embedment ratio of the pipeline increases the uplift resistance capacity but also reduces the efficiency of it.

- Increasing the stiffness of elements of the grid-anchor and geogrid does not have a significant effect on the the uplift resistance capacity of pipelines. However, the uplift resistance increases significantly by increasing the reinforcement width.

\section{Reference}

1. Faizi, K., JahedArmaghani, D., Sohaei, H., Rashid, A.S.A. and Nazir, R. (2015), "Deformation model of sand around short piles under pullout test", Journal of Measurement, 63, 110-119.

2. Mohri, Y., Kawabata, T. and Fujita, N. (2001), "Large-scale experiment on shallow cover for buried pipeline reinforced with geosynthetics", Journal of Pipeline Systems Engineering and Practice, 52, 1-13.

3. Teng, Y., Stanier, S. A. Gourvenec, S. M. Synchronised multi-scale image analysis of soil deformations, International Journal of Physical Modelling in Geotechnics, 2017,Volume 17, Pages 53-71

4. Rowe, R.K. and Davis, E.H. (1982), "The behavior of anchor plates in sand”, Geotechnique, 32, 025-041.

5. Trautmann, C.H., O'Rourke, T.D. and Kulhawy, F.H. (1985), "Uplift force-displacement response of buried pipe", Journal of Geotech. Eng. ASCE, 111, 1061-1076.

6. Dikin, E.A. (1994), "Uplift resistance of buried pipelines in sand”, Journal of Soils and Foundations, 34(2), 41-48.

7. Finch, M. (1999), "Upheaval buckling and floatation of rigid pipelines: the influence of recent geotechnical research on the current state of the art", Offshore Technology Conference, Houston, Texas.

8. White, D.J., Barefoot, A.J. and Bolton, M.D. (2001), "Centrifuge modeling of upheaval buckling in sand", Int. J. Phys. Model. Geotech., 21, 019-028.

9. Bransby, M.F., Newson, T.A., Davies, M.C.R. and Brunning, P. (2002), "Physical modelling of the upheaval resistance of buried offshore pipelines", 4th International Conference on Physical Modelling in Geomechanics, St. Johns, 899-904.

10. Cheuk, C.Y., White, D.J. and Bolton, M.D. (2005), "Deformation mechanisms during the uplift of buried pipelines in sand", Proc. XVIth Int. Conf. Soil Mech. and Geotech. Eng., Osaka, 1685-1688.

11.White, D.J., Cheuk, C.Y. and Bolton, M.D. (2008), "The uplift resistance of pipes and plate anchors buried in sand," Geotechnique, 58, 771-779.

12.Choobbasti, A.V., Vahdatirad, M., FirouzianBandpey, S., Barari, A. and Rezaei, D. (2009), "Modeling of the uplift response of buried pipelines", Electron. J. Geotech. Eng., 14, 001-015.

13.Lee, H. (2010), "Finite element analysis of a buried pipeline", Master's Thesis, University of Manchester, Manchester.

14.Huang, B., Liu, J., Lin, P. and Ling, D. (2014), "Uplifting behavior of shallow buried pipe in liquefiable soil by dynamic centrifuge test", The Scientific World Journal, Article ID 838546.

15.Newson, T.A. and Deljoui, P. (2006), "Finite element modelling of upheaval buckling of buried offshore pipelines in clayey soils", Soil and Rock Behavior and Modeling, 351-358.

16.Thusyanthan, N.I., Ganesan, S.A. Bolton, M.D. and Allan, P. (2008), "Upheaval buckling resistance of pipelines buried in clayey backfill", 18th International Offshore and Polar Engineering Conference, Vancouver, British Columbia, Canada, 6-11.

17.Selvadurai, A.P.S. (1989), "The enhancement of the uplift capacity of buried pipelines by the use of geogrids", Journal of Geotechnical and Geoenvironmental Engineering ASCE, 124(8), 211-216.

18.Jacobs $\mathrm{F}$ et al. Investigation of kinematic behavior and earth pressure development of geogrid reinforced soil walls. Transport Geotech (2016), http://dx.doi.org/10.1016/j.trgeo.2016.07.004

19.Mosallanezhad, M., Hataf, N., Ghahramani, A. (2008), Experimental study of bearing capacity of granular soils, reinforced with innovative grid-anchor system. Geotech. Geol. Eng. 26 (3), 299-312. 
20.Alamshahi, S., Hataf, N. (2009), "Bearing capacity of strip footings on sand slopes reinforced with geogrid and grid-anchor. Geotext.Geomembr", 27 (3), 217-226.

21.Mosallanezhad, M., Sadat Taghavi, S.H., Hataf, N., Alfaro, M.C. (2016), Experimental and numerical studies of the performance of the new reinforcement system under pull-out conditions. Geotext.Geomembr. 44 (1), 70-80

22.Kok-Kwang Phoon \& Chong Tang (2019): Characterisation of geotechnical model uncertainty, Georisk: Assessment and Management of Risk for Engineered Systems and Geohazards, DOI: 10.1080/17499518.2019.1585545

23.White, D.J., Take, W.A. and Bolton, M.D, (2003). Soil Deformation Measurement Using Particle Image Velocimetry (PIV). Geotechnique, Volume 53, No. 7: 619-631

24.Take, W.A. (2015) .Thirty - Sixth Canadian Geotechnical Colloquium: Advances in Visualization of Geotechnical Processes through Digital Image Correlation. Canadian Geotechnical Journal, doi: $10.1139 / \mathrm{cgj}$ - 2014 - 0080

25. Soga K., Ewais A., Fern J., Park J, (2019) Advances in Geotechnical Sensors and Monitoring. In: Lu N., Mitchell J.,Geotechnical Fundamentals for Addressing New World Challenges. Springer Series in Geomechanics and Geoengineering. Springer, Cham

26.M. Kanitza, A. Hager, J. Grabe, C .Goniva, Numerical and experimental analysis of the extraction mechanism of an anchor plate embedded in saturated sand, (2019),Computers and Geotechnics, Volume 111, July 2019, Pages 191-201

27.Nuria M. Pinyol, Mauricio Alvarado, Novel analysis for large strains based on particle image velocimetry, Canadian Geotechnical Journal, 2017, 54(7): 933-944

28.Itasca. (2012), FLAC-3D Version 5.0.Itasca Consulting Group, Inc., Minneapolis.

29.Niroumand, H., Kassim, K.A. and Nazir, R. (2013), "The influence of soil reinforcement on the uplift response of symmetrical anchor plate embedded in sand", Journal of Measurement, 46, 2608-2629. 